Farum

Sociológico

\section{Forum Sociológico}

Série II

35 | 2019

Arte urbana: Contextos, tendências e desafios

\title{
O terceiro lado do muro. A arte e as suas cidades
}

The third side of the wall. Art and its Cities

\section{Chiara Pussetti e Vitor Barros}

\section{(2) OpenEdition}

\section{Journals}

Edição electrónica

URL: https://journals.openedition.org/sociologico/8640

DOI: $10.4000 /$ sociologico. 8640

ISSN: 2182-7427

\section{Editora}

CICS.NOVA - Centro Interdisciplinar de Ciências Sociais da Universidade Nova de Lisboa

\section{Edição impressa}

Paginação: 51-59

ISSN: 0872-8380

\section{Refêrencia eletrónica}

Chiara Pussetti e Vitor Barros, «0 terceiro lado do muro. A arte e as suas cidades», Forum Sociológico [Online], 35 | 2019, posto online no dia 11 dezembro 2019, consultado o 31 març 2022. URL: http:// journals.openedition.org/sociologico/8640 ; DOI: https://doi.org/10.4000/sociologico.8640 


\title{
O TERCEIRO LADO DO MURO. A ARTE E AS SUAS CIDADES ${ }^{1}$ THE THIRD SIDE OF THE WALL. ART AND ITS CITIES
}

\author{
Chiara Pussetti ${ }^{2}$ \\ Instituto de Ciências Sociais, Universidade de Lisboa (ICS - ULisboa) \\ Vitor Barros \\ Instituto de Ciências Sociais, Universidade de Lisboa (ICS - ULisboa)
}

\begin{abstract}
Resumo
Este ensaio pretende, a partir da observação etnográfica de expressões de arte urbana embemáticas na cidade de Lisboa e de uma reflexão comparativa entre distinctive cities (Markusen, 2004), criar uma narrativa que percorra os principais vectores da transformação do universo da arte urbana na última década. Tentando reproduzir o estilo ensaístico e as modalidades narrativas que estiveram na origem desta reflexão, traçaremos um percurso através dos debates principais sobre arte urbana, mostrando no seu conjunto a heterogeneidade dos processos e das forças que condicionam a presença artística no espaço urbano e delineando futuras hipóteses de pesquisa. 0 objetivo desta reflexão será conduzir o leitor a a) observar os efeitos da progressiva influência da gramática do empreendedorismo; b) inquirir os dispositivos regulatórios criados - novos agentes, instituições e legislação, seja para punir ou fomentar a sua produção; c) analisar a relação material e sensorial da arte urbana com a própria cidade - da sua normativização estética à reificação da propriedade ou à consolidação da "cidade legislada"; d) integrar a arte urbana no processo mais alargado de divisão estrutural da cultura que, por um lado, é absorvida pela narrativa hegemónica das indústrias criativas e, por outro, permeia o tecido social, promovendo a participação ou a coesão social; e) examinar estas transformações da arte urbana no quadro da construção da cidade contemporânea e, em particular, do seu espaço público.
\end{abstract}

Palavras-chave: arte urbana, cidade, indústrias culturais, regeneração urbana

\section{Abstract}

Based on a ethnographic observation of empirical urban art expressions in the city of Lisbon and on a comparative reflection between "distinctive cities" (Markusen, 2004), this essay aims to create a narrative that covers the main vectors of the transformation of the urban art universe in the last decade. Trying to reproduce the essayistic style and narrative modalities that were the origin of this reflection, we will trace a path through the main debates about urban art, showing together the heterogeneity of the processes and forces that condition the artistic presence in the urban space and outlining future hypotheses of research. The purpose of this reflection will be to lead the reader to a) observe the effects of the progressive influence of the grammar of entrepreneurship; b) inquire into the regulatory dispositifs created - new agents, institutions and legislation either to punish or encourage its production; c) analyze the material and sensorial relationship of urban art with the city itself - from its aesthetic normativization, to the reification of property or the consolidation of the "legislated city"; d) integrate urban art into the broader process of structural division of culture, which, on the one hand, is absorbed by the hegemonic narrative of the creative industries and, on the other, permeates the social fabric, promoting social participation or cohesion; e) examine these transformations of urban art in the context of the construction of the contemporary city and, in particular, of its public space.

Keywords: urban art, city, cultural industries, urban regeneration 
As respostas vão da irritação ao silêncio. Há graffiti por todo o país, dos centros históricos aos subúrbios. E nós, que vivemos rodeados por eles, nem sabemos bem o que são.

Joana Amaral Cardoso, A arte clandestina pinta ou suja as ruas? Jornal Público, 28 de fevereiro de 2007

A 30 de janeiro de 2019, quase doze anos depois desta citação, uma edição da revista Time Out Lisboa dava destaque aos grandes 50 projetos do futuro próximo da cidade, cuja execução promete modificações substanciais na estrutura e circulação da capital do país. Como peça central da edição, era publicada uma entrevista ao presidente da Câmara Municipal de Lisboa, Fernando Medina, na qual explanava a sua visão para o futuro da cidade, enquanto refletia igualmente sobre as fortes transformações urbanas dos tempos mais recentes, em particular os desafios inerentes às crescentes pressões turísticas e habitacionais ou o papel da cultura e das indústrias criativas na regeneração de uma cidade em contexto de pós-crise económica.

Da peça jornalística salta também à vista a primeira imagem, de página inteira, onde Fernando Medina é fotografado no terço inferior, dando relevo a uma obra de arte que ocupa toda a parede atrás de si, "[um]a peça de Vhils que dá charme ao seu gabinete". Doze anos atrás seria talvez difícil de acreditar que um artista oriundo do universo da street art em Portugal tivesse um lugar tão destacado - e apresentado de forma tão natural - num gabinete de tão grande responsabilidade governativa, mas é uma imagem que, de algum modo, espelha a enorme transformação que a cidade de Lisboa - tal como muitos centros urbanos um pouco por todo o mundo - teve em relação a esta prática artística. Na verdade, é difícil hoje dissociar a visibilidade internacional de Lisboa do impacto que teve a disseminação da arte urbana no seu território durante esse período. A profusão de obras, artistas, projetos e eventos é dos elementos constantemente referidos tanto pelos media estrangeiros ${ }^{3}$ como pela própria promoção institucional da cidade, tendo-se tornado um elemento-chave dos processos de city-branding destinados a melhorar a competitividade de Lisboa no mercado de turismo global (Liu, 2012).

No entanto, a grande transformação não se processou apenas na relação das cidades com a arte urbana, mas também na relação da arte urbana com a própria cidade, com o campo da arte e, finalmente, consigo mesma. Nascida de uma expressão subcultural de visibilização e reivindicação identitária e territorial, a arte urbana está iminentemente ligada às próprias assimetrias do desenvolvimento urbano e, portanto, de relações materiais e simbólicas entre o centro e periferia - no espaço da cidade, no enquadramento legal, no reconhecimento social. Ainda que o movimento de "institucionalização" da arte urbana não seja de agora, como provam os casos de Keith Haring e Jean-Michel Basquiat no establishment artístico nova-iorquino no início da década de 80, os últimos 15 anos trouxeram mudanças extremamente significativas. Exposições como Spank the Monkey no BALTIC Centre for Contemporary Art (Newcastle upon Tyne, 2006), Graffiti no Brooklyn Museum (Nova Iorque, 2006), Street Art na Tate Modern (Londres, 2008) ou Art in the Streets no Museum of Contemporary Art (Los Angeles, 2011) trouxeram visibilidade e legibilidade à expressão artística "da rua", criando pontes entre uma produção frequentemente vista como crime, vandalismo ou atentado à propriedade privada e algo que podia ser considerado arte contemporânea (Bengtsen, 2015) e, portanto, passível de comunicar com as suas estruturas hegemónicas, os seus gatekeepers legítimos: a galeria, o curador, o museu, a casa de leilões. No entanto, o processo de legitimação não se reduz à absorção da arte urbana dentro destas estruturas, mas encontra-se igualmente na transferência da sua eficácia simbólica para o espaço público, como o demonstra a percepção alargada de qualquer conjunto de intervenções num bairro ou no âmbito de um evento como um "museu ao ar livre" ou "galeria a céu aberto". Também Portugal faria parte deste movimento: o projeto "Red Bull Street Gallery" celebraria o Dia Internacional dos Museus, a 18 de maio de 2007, com dez intervenções de arte urbana colocadas junto a dez museus, com o intuito de promover o debate "Arte na Rua vs. Arte no Museu" logo depois de, em novembro de 2006, a agência Vera Cortês ter convidado Alexandre Farto (aka Vhils) e Miguel Maurício a expor na Galeria Promontorio Arquitectos questionando a relação que uma "arte delinquente" poderia desenvolver com "formatos socialmente aceites".

Doze anos depois, Vhils não está apenas no escritório de um governante ou numa galeria importante e, definitivamente, está muito mais perto dos "formatos socialmente aceites" que da "arte delinquente": é um dos artistas portugueses de maior reputação internacional, desenvolve peças comissionadas e festivais de arte urbana à volta do mundo, é parceiro na criação de um dos primeiros museus exclusivamente dedicados à arte urbana, é embaixador da estratégia nacional para o empreendedorismo Startup Portugal e, através da sua agência criativa Solid Dogma, ganha prémios de design e publicidade a desenvolver campanhas para marcas como a Levi's, Seat, Mini, Renault ou Super Bock. A sua produção é, por um lado, quase exclusivamente legalizada, quando não comissionada, e funciona dentro de quadros fortemente institucionais; por outro, é fonte de criação de valor com a sua inserção em circuitos de mercantilização e é parte da negociação com entidades governativas que 
a instrumentalizam, seja para efeitos de promoção turística, regeneração urbana ou consolidação das indústrias criativas.

Sendo grande parte da expressão da arte urbana de natureza ilegal e subversiva, dominada por uma certa contestação, justamente, da arte e do urbano, não é de admirar que, neste circuito marcado pela progressiva legalização, institucionalização, mercantilização e instrumentalização, surjam vozes críticas que questionam o potencial crítico ou radical da linguagem de artistas consagrados como Vhils. Esta crítica torna-se, portanto, o fechamento desse mesmo circuito, presa a uma série de pressupostos dicotómicos como a independência artística vs. mainstream, a liberdade crítica vs. o condicionamento político, projetos de base comunitária ( 0 artista-engajado) vs. projetos de transformação urbana (o artista-gentrificador), entre outros (Ley, 2003; Cameron \& Coaffee, 2005).

Neste ensaio, gostaríamos de refletir sobre as contradições interentes às práticas e políticas da arte urbana, tomando como ponto de partida uma selecção de obras, artistas ou projetos de arte urbana que foram alvos de forte atenção mediática na cidade de Lisboa e pondo estes exemplos emblemáticos de distinctive cities (Markusen, 2004) em tensão comparativa com eventos urbanos que provêm de outros contextos mas revelam dinâmicas e problemáticas parecidas. Com o termo distinctive city, a autora refere-se a como o branding (re)presenta a identidade da cidade, criando imaginários de unicidade e distintividade simbólica na produção e no consumo da oferta (Markusen \& Schrock, 2006).

Neste sentido, Lisboa, "a cidade museu a céu aberto" (Texeira Pinto, 2018), é uma cidade "boa para pensar" as conexões e as relações quotidianas entre arte e espaço público, com os seus conflitos, paradoxos e negociações. O processo da construção de Lisboa como "cidade das artes" é fortemente definido e organizado pela municipalidade, e em particular pela Galeria de Arte Urbana, que gere a regulamentação de cada manifestação artística no espaço público - regularizando através de um sistema de prémios e penalidades os seus conteúdos, formas e linguagens. Através da apresentação de casos que consideramos particularmente emblemáticos, iremos evidenciar como a arte urbana não se encontra isolada do processo mais alargado do processo de governamentalização do sector cultural, nem sequer do seu recente processo de divisão estrutural: de um lado, a cultura que é absorvida pela narrativa hegemónica das indústrias criativas e, portanto, pela lógica de mercado; do outro, a cultura que permeia o tecido social através de uma fetichização do seu efeito na população, promovendo a cidadania, a educação, a identidade, a participação ou a coesão social. Ambos os lados, não um contra o outro nem um mais do que outro, são duas faces do mesmo processo de construção da cidade contemporânea e, em particular, do seu espaço público.

Tentando reproduzir o estilo ensaístico e as modalidades narrativas que estiveram na origem desta reflexão, traçaremos um percurso analítico que delineia os debates de base que definem o tema em questão, sem, todavia, neste ensaio querer desenvolver uma reflexão teórica aprofundada ou uma apresentação exaustiva das principais abordagens disciplinares. Por outras palavras, queremos lançar, através de um estilo narrativo propositatamente discursivo, questões para o debate, delinear os pontos mais interessantes e, ao mesmo tempo, mais problemáticos, ou ainda abrir conexões entre diferentes exemplos obervados ou experienciados durante anos de prática etnográfica no âmbito da arte urbana. Não é, todavia, nossa intenção apresentar aqui os dados resultantes de uma observação etnográfica clássica, mas reconstruir processos reflexivos, na ideia de que toda a etnografia e, de maneira mais geral, qualquer pesquisa social, além dos métodos e da retórica epistemológica utilizada, é uma narração de momentos heterogéneos, muitas vezes contraditórios e ambíguos, que nos obrigam a um posicionamento ao mesmo tempo pessoal e político. Através deste exercício exploratório e de uma escoIha narrativa experimental, pretendemos, portanto, não apresentar uma análise teórica detalhada, mas uma narração - marcada para um certo ecletismo teórico e empírico (Rankin, 2011) - que mostre no seu conjunto a heterogeneidade dos processos e das forças que condicionam a presença artística no espaço urbano. Os temas que nos chamaram a atenção são múltiplos: os fenómenos da institucionalização e mercantilização, num campo cada vez mais sujeito a lógicas de empreendedorismo, dos próprios artistas aos produtores culturais, passando pelos guias turísticos; os dispositivos regulatórios criados, da abertura de concursos à obtenção de autorizações; a relação material, simbólica e sensorial da arte urbana com a própria construção da cidade, da sua normativização estética à reificação da propriedade, da securitização do espaço público à consolidação da "cidade legislada".

\section{Cidade: questões iminentes}

Não será grande surpresa, por estes dias, numa tarde soalheira de fim-de-semana, encontrar largas centenas de pessoas a visitar o Panorâmico de Monsanto, um icónico mas abandonado edifício no topo do importante parque florestal da cidade de Lisboa. Distinguindo-se pelas vistas únicas de $360^{\circ}$ sobre a capital, o edifício esteve abandonado entre 2001 e 2017, altura em que a Câmara Municipal interveio com operações de limpeza e segurança, dando-Ihe a designação de Miradouro e garantindo o acesso gratuito ao público durante o dia. 
À entrada do recinto é praticamente impossível não ver as gigantes letras espelhadas com a inscrição \pm REAL \pm do artista Miguel Januário, ao mesmo tempo um preâmbulo e uma legenda da excentricidade e singularidade deste espaço. A obra foi realizada no âmbito da 3. a edição do Festival Iminente, criado e curado por Vhils e co-organizado pela Câmara Municipal de Lisboa, que ocupou o edifício em setembro de 2018, juntando 55 nomes da arte e da música numa "montra das subculturas urbanas", celebrando o ambiente multicultural e cosmopolita de Lisboa. Das várias obras deixadas pelo festival, uma em particular concentra as atenções e filas de pessoas que esperam o momento ideal para fotografar e filmar: um retrato realizado por Vhils, com a sua estética mundialmente reconhecida, da ativista brasileira Marielle Franco, assassinada 6 meses antes no Rio de Janeiro. Parte da campanha "Brave Walls" desenvolvida pela Amnistia Internacional, o mural teve impacto internacional e foi globalmente celebrado pelo seu cariz crítico e interventivo - nas palavras de Pedro Neto, diretor executivo da Amnistia Internacional Portugal, uma "expressão da Arte, de forma pacífica e audível, a exigir justiça e direitos humanos"4.

Em vez de olhar para este fenómeno na óptica da legalidade ou ilegalidade, da institucionalização ou potencial crítico, da comercialização ou autenticidade, será talvez mais interessante olhar para dois campos da expressão e produção a partir dos quais existe uma normalização da "arte na cidade", mas também da "cidade através da arte" (Guinard \& Molina, 2018). O primeiro é o do próprio processo de "eventificação" (Jacob, 2013), à medida que a política cultural das cidades se move progressivamente de "instituições" para "eventos" (Henningsen et al., 2015) e a sua geografia vai sendo moldada para acomodar um preenchido calendário anual de acontecimentos culturais. Esta "festivalização" na definição de Häussermann e Siebel (1993) - a um mesmo tempo da cultura e da própria cidade, com o encontro entre arte, espaço público, grandes audiências e cobertura mediática tornaram-se "ferramentas poderosas para atrair investidores, estimular indústrias orientadas para o consumo e redesenhar a imagem e reputação de uma cidade" (Aubry et al., 2015). Mas os efeitos de um evento estão muito além da sua constituição como pólo de atração. No caso do Iminente, um espaço aberto ao público foi fechado e tornado acessível, mediante a compra de um bilhete (10€), a um máximo de 4500 pessoas por dia. Foi ainda imposto o cumprimento de normas de segurança que impediam os espectadores de entrar para o recinto não só com objetos perigosos, mas também com animais, comida e bebida e material profissional de fotografia, vídeo e som. A construção do festival torna-se, portanto, um instrumento de disciplinamento. Estas "privatização" e "securitização" do espaço através do "evento" não só transformam de forma evidente, por exemplo, o artista em "produtor-empreendedor" e o público em "audiência-espectador", mas revelam de forma mais global um conjunto de estratégias, técnicas e discursos através dos quais a "vida quotidiana da cidade é moldada em espaços, relações e práticas de segurança, mercantilização e entretenimento" (Pavoni, 2015). Ainda temos de considerar que os festivais são promovidos por instituições governamentais, apoiados por investidores e patrocinadores, determinados pela concessão de ocupação de espaços, pela obtenção de permissões e por negociações que transformam o festival na versão normalizada, instrumentalizada e domesticada da arte urbana, para finalidades de promoção de áreas específicas da cidade, de desenvolvimento económico ou de atração turística, através de um processo de branding da cidade. O festival opera por outras palavras como um instrumento de "imagineering technology" (Ren, 2007).

O segundo tem que ver com o processo de "patrimonialização", que torna visível um conjunto de ambiguidades na relação entre arte, política e espaço urbano. Enquanto o edifício foi apropriado por writers, durante o tempo em que esteve abandonado, essas atividades eram classificadas como "vandalismo" que "danificavam o património"; logo depois, porém, foram englobadas pelos próprios curadores do festival como parte do espólio artístico do espaço, deste modo enevoando não só a distinção entre prática artística e criminosa de uma mesma peça, mas o seu efeito vis-à-vis o património da cidade. Na sequência deste processo, importa também interrogar a complexidade de respostas de preservação da própria arte urbana, em si mesma quase antagónica à sua natureza efémera. A consciencialização do valor intrínseco e social da obra levou cada vez mais à tentativa da sua preservação, principalmente do "vandalismo" por parte de outros graffiters - o uso de um verniz especial no Mural ao 25 de Abril da Associação Underdogs na parede da Faculdade de Ciências Sociais e Humanas da Universidade Nova de Lisboa depois de ter sido vandalizado com cruzes suásticas, ou a colocação de plexiglas transparente no mural História de Lisboa de Nuno Saraiva nas Portas do Sol, no bairro de Alfama, são apenas alguns exemplos.

Isto não significa que várias obras não acabem por ser destruídas, principalmente em grandes projetos de renovação urbana, caso de duas obras famosas de Vhils - uma com Pixel Pancho, para dar origem ao novo terminal de cruzeiros de Lisboa, e outra na antiga Fábrica da Sidul, em Alcântara, para dar origem a um mega-empreendimento de habitação e escritórios num valor estimado de 100 milhões de euros - dando origem a alguma visibilidade mediática e bastantes críticas da população. 
Existem, de resto, casos a nível internacional que se revelaram mais extremos, como o da ação interposta por um grupo de 21 artistas contra a pintura e posterior demolição do edifício 5Pointz, considerado um templo do graffiti em Long Island, que valeu uma multa de 6,7 milhões de dólares ao proprietário. Uma outra nuance diz respeito ao uso da arte urbana já em projetos de renovação arquitectónica como o do projeto de intervenção num edifício de Agostinho Ricca no Porto, que incluiria um mural de Vhils, mas que gerou uma onda de crítica que via o projeto como um ataque à preservação do património arquitectónico do Porto.

Finalmente, e voltando ao Panorâmico de Monsanto, quando a edilidade declara que o festival "vai mostrar um novo potencial de utilização do espaço e vai mudar a forma como nós olhamos para ele e sobre as potencialidades que terá futuramente" isso deixa algumas pistas sobre a forma como se percepciona a relação entre a arte urbana e o potencial de reabilitação da cidade. Basta tomar como exemplo as recentes gravações do novo álbum, Madame $X$, da artista Madonna, realizadas no edifício, celebrando na sua conta de Instagram a "magia de Lisboa" através da sua "arte urbana", aparecendo constantemente rodeada de graffitis e inclusivamente a graffitar um $X$ vermelho numa parede, enquanto o espaço foi condicionado ao público, impedindo qualquer registo através de câmaras ou telemóveis, para proteger a campanha de publicidade programada. Este exemplo de potencial de utilização introduz, deste modo, por um lado, questões em torno da preservação e regeneração do património, principalmente a partir do momento em que o reconhecimento social e institucional da arte urbana a transforma, de certo modo, a ela própria, num elemento patrimonial material e imaterial - a sua inscrição física e a cultura urbana que representa - e, por outro, questões em torno da normalização de dispositivos técnico-legais de entretenimento e segurança na reconstrução do espaço.

\section{Economia: capital (e) cultural}

Ainda que o universo do graffiti tenha beneficiado da associação com o establishment artístico - a partir da qual vários artistas passaram a ter rendimentos da venda de obras de arte e merchandising - e da aproximação estratégica dos governos locais - a partir da qual vários artistas passaram a exercer a sua atividade legalmente e tendencialmente paga -, tal não quer dizer que tenha sido um processo linear e sem sobressaltos. Alguns exemplos são as exposições não autorizadas de obras de Banksy, a performance do próprio Banksy de ativar uma destruidora de papel escondida na sua Girl with a Balloon depois de ser leiloada na Sotheby's por um milhão de libras, ou a decisão de
Blu de cobrir de tinta cinzenta todas as suas obras na cidade de Bolonha como crítica a uma "cidade que, por um lado, criminaliza o graffiti, leva writers de 16 anos a tribunal, louva o 'decoro urbano' e, por outro, congratula-se a si mesma enquanto berço da arte urbana e quer recuperá-la para valorização no mercado" 6 . Em todo o caso, se a arte urbana foi apropriada e incorporada no mainstream pelo mundo artístico e por instituições governamentais, falta seguramente olhar para as grandes marcas comerciais (Lombard, 2013), um casamento rea British Airways usou um mural mo rcas comerciais (Lombard, 2013), casamentocuperda arte urbana a transforma, de certo modo, não menos acidentado.

Em 2015 o New York Times decidiu fazer um perfil sobre o designer Jeremy Scott e a sua marca de roupa Moschino, elogiando a sua última coleção e a sua relação com a cultura pop. No cerne da coleção estava uma clara inspiração da estética do graffiti, usado não apenas em várias peças da coleção, mas também em toda a produção do espetáculo em torno das galas e dos desfiles, incluindo celebridades como Madonna e Katy Perry, que posavam ao lado de um Rolls-Royce grafitado. Pouco tempo depois, a internet borbulhava com uma ação judicial interposta pelo artista Rime à Moschino: o padrão usado na coleção era afinal uma cópia do seu mural Vandal Eyes pintado em Detroit em 20127 . Não é um caso único no mundo da moda: precisamente um ano antes, os artistas Revok, Reyes e Steel de São Francisco tinham também interposto uma ação judicial contra a marca Roberto Cavalli que tinha não apenas reproduzido um mural na sua coleção mas sobreposto a sua própria assinatura à obra, lançando ainda mais dúvidas sobre a questão da autoralidade ${ }^{8}$. Outros casos sucederam-se entretanto, como quando a campanha holandesa "McDonald's presents the vibe of Bushwick" enfureceu um conjunto de artistas cujos murais apareciam no vídeo promocional sem autorização ${ }^{9}$, ou quando a companhia aérea British Airways usou o mural Chance Street da artista MadC em Shoreditch numa campanha publicitária ${ }^{10}$.

Os contornos do debate mediático e das acusações e defesas de ambas as partes é particularmente esclarecedor. O caso da Moschino é, desde logo, particularmente relevante pelo facto de a defesa legal argumentar que não se tratava de uma infração à lei de copyright porque o graffiti é um ato de vandalismo, e portanto ilegal. Noutros casos argumenta-se que esta expressão artística é propriedade pública e, portanto, de uso livre, ou que se encontra no âmbito do uso razoável do direito à paisagem, como acontece, por exemplo com muitos monumentos. Da parte dos artistas, é pedida não apenas uma indemnização por abuso de copyright, mas na maior parte dos casos há uma reação de desagrado do aproveitamento da sua produção para marcas de luxo e glamour ou simplesmente de gran- 
des cadeias multinacionais como a McDonald's, que são vistas como a antítese dos valores da sua prática artística. Deste modo, muitos artistas procuram um equilíbrio cuidado entre o valor artístico e comercial, preferindo colaborar, por exemplo, com acessórios de moda ou automóveis de cariz desportivo, mais próximos dos códigos das subculturas urbanas. Em todo o caso, estes episódios são ilustrativos das contradições existentes em torno da exploração comercial da arte urbana mas também, em geral, de como se tornou uma mercadoria tão desejável na procura de aumentar a street cred de uma empresa ou produto, capitalizando uma aproximação à cultura jovem e urbana.

Um interessante exemplo desta relação complexa em Portugal foi o sucesso mediático em torno do artista Coruja durante o ano de 2018. Desenhando corujas com diversas técnicas da linguagem do graffiti por todo o país, e alimentando competentemente a sua presença nas redes sociais, Coruja aparece legitimamente como um novo nome da arte urbana. De seguida, os eventos sucedem-se rapidamente: a marca de cerveja Super Bock lança uma nova gama de cerveja "especial" designada Coruja, apelando ao crescente mercado da cerveja artesanal; o artista Coruja reage com desagrado fazendo ad hacking em cima dos cartazes e mupis da Coruja com as suas próprias corujas; a marca Super Bock lança uma campanha de procura do artista-vândalo; finalmente, revela-se a identidade de Coruja (uma crew composta por The Caver, Contra, Frame 01, Glam, Kruella, MAR, Mário Belém, Mosaik e Samina) numa campanha publicitária de ativação de marca orquestrada pela agência Solid Dogma, num simulacro da técnica e estética da arte urbana - não guerrilla marketing mas um marketing stunt - desenvolvido colaborativamente com os próprios artistas, mas deixando questões sobre o impacto da normalização destas práticas na cidade. Para a Solid Dogma, os prestigiados prémios de Design Meios e Publicidade trouxeram em 2019 variadíssimos galardões, incluindo o de Projeto Integrado para a campanha "Coruja", o Grande Prémio para o Festival Iminente e, para si, própria, o de "Agência do Ano".

\section{Comunidade: dogmas e muros}

A casa significa o primado da necessidade individual, e a rua pressupõe que um imperativo superior, que é a exigência da coisa pública, prevaleça sobre a casa. A rua representa a ordem ou lei geral a que se submete o capricho ou a vontade individual.

Carta Estratégica de Lisboa 2010-2024

Embora este artigo não tenha como objetivo mergulhar nas distinções e categorizações inerentes ao próprio universo da arte urbana, é necessário enfatizar a sua diversidade e complexidade, e as diversas e complexas respostas a que está sujeita (Campos, 2012, 2015). Sobretudo, observar processos de mainstreaming não significa deduzir algum tipo de colonização vitoriosa da arte urbana como um todo no panorama cultural. A celebrização de um certo tipo de arte urbana contemporânea, tendencialmente pictórico, iconográfico, muralista, legal e/ou comissionado - chamado por alguns autores de pós-graffiti (Dickens, 2008) - não alterou de forma significativa (se não intensificou mesmo o processo) a ostracização e criminalização do graffiti de cariz mais tipográfico e as técnicas de street art aplicadas de forma ilegal.

Se é verdade que os governos municipais promovem cada vez mais a arte urbana nos seus programas culturais, existe também uma substantiva criminalização da prática ilegal ${ }^{11}$ e a constitui?)in extremis, ao terrorismo (Iveson, es, foi por diversas vezes declarada treaming da arte urbana $\mathrm{n}$ transforma, de certo modo, ção de técnicas e discursos para a eliminar. Em Lisboa, como em tantas outras cidades, foi por diversas vezes usada a retórica militarizada da "guerra" ao graffiti, associando a prática, in extremis, ao terrorismo (Iveson, 2010). A resposta sócio-legal segue também muitas vezes a abordagem da "tolerância zero", seguindo a importação da teoria criminológica das "janelas partidas", segundo a qual a manifestação visível de comportamento anti-social estimula esse mesmo comportamento por parte de outros - se uma janela de um edifício abandonado aparece partida, seguir-se-ão outras, a menos que se conserte de imediato a janela. 0 graffiti não é, portanto, apenas problemático pela prática em si, mas pela associação com outros tipos de comportamentos "desviantes" frequentes no espaço urbano, tendo-se tornado uma representação visual do próprio "desvio". Numa resposta de limpeza a uma zona considerada problemática em 2016, Vasco Morgado ${ }^{12}$, presidente da Junta de Freguesia de Santo António, declara que vai ser "uma intervenção total, sem abertura de excepções. De cada vez que se fizer um risco ou uma pintura numa parede, nós iremos logo limpar", ou que "o segredo é atacar logo que haja um risco". Assume ainda a vigilância da área - "a Polícia Municipal vai lá estar todos os dias, durante uns tempos" - e os custos avultados das intervenções - "As pessoas nem imaginam o dinheiro que se gasta com esta operações de limpeza. Até para a Câmara de Lisboa é caríssimo". E de facto é. Logo de seguida, o executivo municipal abriria um concurso para a privatização por 3 anos do serviço de remoção de graffitis e cartazes, cujos valores totais se prevê que possam ascender aos 5 milhões de euros, um valor muitíssimo superior ao investido em projetos de arte urbana comissionada.

Uma primeira leitura é a de que, seguramente, existe um movimento muito mais complexo do que o de uma progressiva legalização do graffiti. 
Uma segunda, mais importante, é a de uma certa prudência em ler a obra "legal" como uma "concessão", ou uma "liberdade" dada a uma parte desta expressão artística. Na verdade, ela reforça, por um lado, a noção de propriedade e da relação que um proprietário tem relativamente a um espaço de usufruto público (Young, 2014) e, por outro, uma determinada visão estética e sensorial da cidade, o que é, que aspecto deve ter, de que forma se pode concretizar e usufruir, reduzindo as formas efetivas de construção, circulação, apropriação e negociação sobre o espaço urbano.

Este ponto é relevante para a tentativa feita acima de separar dois segmentos de produção cultural, não redutíveis ao tipo de expressão cultural em si mesma: de um lado, uma produção que mais diretamente se relaciona com a construção política e económica das indústrias culturais e criativas; do outro, uma produção que está intimamente ligada à noção de regeneração urbana desde os anos 90 do século passado, destinada a fomentar valores de cidadania, sensação de pertença e inclusão social (Hall \& Robertson, 2001) entre populações tidas como "vulneráveis" (Pussetti \& Barros, 2012). Na verdade, se a arte urbana ganhou protagonismo, como vimos, no mundo do audiovisual, do design, da publicidade ou da moda, ela tornou-se uma ferramenta poderosa para a retórica da democratização da cultura e o empoderamento das comunidades locais (Bailey et al., 2004).

Conseguimos captar este processo com grande naturalidade no discurso institucional nas áreas periféricas (sociais ou espaciais) da Grande Lisboa. Na Amadora, por exemplo, o projeto "Conversas na Rua" é responsável por mais de 100 intervenções de arte pública mural, que "intensificam o sentimento de pertença de quem aqui habita e sente a cidade como sua"13, enquanto Loures se colocou no panorama internacional com a Galeria de Arte Pública, na Quinta do Mocho, em Sacavém, um processo artístico através do qual se concretizou "uma profunda e significativa alteração nas relações interpessoais na comunidade", um "projeto integrador e promotor de identidade e sentido de pertença que desempenhará um papel muito significativo no processo de integração e transformação social"14.

$\mathrm{Na}$ cidade de Lisboa, a criação da Galeria de Arte Urbana em 2008, uma entidade específica dentro do Departamento do Património Cultural, foi um driver fundamental na promoção e regulação da arte urbana na cidade, tendo ajudado a promover inúmeros projetos e artistas que criaram referências visuais icónicas no centro da cidade. Mais recentemente, foram responsáveis pela criação do festival MURO, com duas edições em áreas frequentemente estigmatizadas e tidas como "problemáticas": o bairro Padre Cruz em 2016 e a zona norte de Marvila, nos bairros das Salgadas, Quinta Marquês de Abrantes e Quinta do Chalé em 2017. As intervenções ficam marcadas pela dimensão, pelos artistas internacionais convidados e pela projeção mediática, mas também por outros dispositivos menos evidentes mas produtores de uma sensação de controle de um espaço tido como "difícil de governar". A cartografia cuidada do território para divulgação das obras criadas, o remapeamento cognitivo e sensorial do bairro a partir do novos referentes visuais, a circunscrição do evento com horários previstos, o licenciamento da produção artística, a formação de guias turísticos dentro da comunidade, todos estes dispositivos contribuem para a imagem de uma cidade compartimentalizada, organizada no tempo e no espaço, cujos agentes locais podem ser inseridos numa lógica de mercado e cuja intervenção se faz em função dos direitos de propriedade, o que Young (2014) descreve como a "cidade legislada", um "espaço no qual um determinado tipo de experiência é encapsulada e produzida através da regulação do espaço, temporalidade e comportamento".

\section{Pistas para futuras reflexões}

Nos últimos anos a literatura em torno do uso instrumental da cultura na regeneração urbana tem crescido consideravelmente, analisando o impacto de mega-eventos (como a Capital Europeia da Cultura), equipamentos culturais de referência (o efeito "Bilbao"), ou a criação de distritos artísticos e de aglomeração cultural na agenda política para o desenvolvimento local e competição internacional (Liu, 2012; Aubry et al., 2015; Pavoni, 2015; Skrede, 2015). O caso de Lisboa, embora relativamente pouco trabalhado quando comparado com as suas congéneres europeias, representa um campo rico e complexo devido à forma assertiva como a cidade definiu a cultura, no meio de uma severa crise económica, como um catalisador vital da regeneração de um centro histórico decadente. Este contexto coincide com a explosão do reconhecimento internacional da arte urbana, que levou à tentativa de apropriação da sua linguagem, formato, conotação e públicos por parte do establishment artístico, do sector governamental e do universo comercial, num processo não isento de críticas e dúvidas vindas de fora, mas também de dentro do próprio campo.

Esta ambiguidade não é certamente estranha a muitos artistas e produtores culturais (Pussetti \& Barros, no prelo), especialmente àqueles que trabalham preferencialmente no espaço público, para quem a sua expressão artística se relaciona de forma mais ou menos evidente com a visibilização de questões sociais e políticas e que eventualmente trabalham de perto com as populações locais - o que foi descrito como "new genre public art" (Lacy, 1994) - e que alguns autores expressaram numa dialéctica entre o "Carnaval" e o "espetáculo": 
The carnival is the vernacular, bottom-up, potentially subversive festive event, while the spectacle is the top-down strategic pageant orchestrated by the powers that be. Artists perhaps most often want to create on the side of the carnival (...) But in the current economic and political context, artists find themselves and their works corralled into city-boosting spectacles (Radice \& Boudreault-Fournier, 2017).

Do tag clandestino ao mural legalizado, do projeto participativo à obra comissionada, da intervenção no armazém pós-industrial à empena de bairro social, do criminoso à celebridade, seria muito tentador observar as fortes transformações da arte urbana à luz desta dicotomia - e, por inerência, ficarmos presos a um conjunto de construções demasiado rígidas: legal/ilegal, institucionalizado/autêntico, poder/ resistência, estética/política, governo/comunidade. No entanto, analisando as dinâmicas intrincadas dessas transformações, vemos que estamos talvez mais perto de movimentos complexos de 'carnavalização do espetáculo' e de 'espectacularização do Carnaval', como apontam os exemplos explorados ao longo destas linhas. Ao focarmo-nos na expansão da gramática do empreendedorismo e da competitividade das indústrias culturais e criativas, na consolidação da 'cidade legislada', na securitização do espaço público ou nos mecanismos despolitizadores dos projetos comunitários e participativos, procurámos, deste modo, lançar novas pistas para a análise da arte urbana e do desenvolvimento e regeneração da cidade contemporânea.

\section{Notas}

${ }^{1}$ Esta pesquisa foi financiada pelo projeto Regeneration and Optimisation of Cultural heritage in creative and Knowledge cities - ROCK, que recebeu financiamento do programa de investigação e inovação da União Europeia Horizonte 2020 ao abrigo do Acordo de Subvenção no. 730280.

2 Este trabalho é financiado por fundos nacionais através da FCT - Fundação para a Ciência e a Tecnologia , I.P., no âmbito da celebração do contrato-programa previsto nos números 4,5 e 6 do art. ${ }^{\circ} 23 .{ }^{\circ}$ do D.L. n. ${ }^{\circ}$ 57/2016, de 29 de agosto, alterado pela Lei n. ${ }^{\circ}$ 57/2017, de 19 de julho.

${ }^{3}$ Cf. entre outros: https://theculturetrip.com/europe/ portugal/articles/a-walking-tour-of-lisbons-best-street-art/;

https://www.timeout.com/lisbon/art/lisbon-street-art-what-you-cant-miss;

https://www.theguardian.com/travel/2011/jan/29/ graffiti-street-art-lisbon-portugal;

https://www.cbsnews.com/news/lisbon-street-artist-vhils-alexandre-farto-scraping-and-carving-art-into-cityscapes/

${ }^{4}$ https://www.amnistia.pt/marielle-mural-by-vhils-pt/
5 http://www.cm-lisboa.pt/en/city-council/news/detalhe-da-noticia/article/iminente-celebrates-reopening-of-panoramico-do-monsanto

6 Post 'Street Artist \#Blu Is Erasing All The Murals $\mathrm{He}$ Painted in \#Bologna', publicado no blog Wu Ming, 12 de março de 2016, em https://www.wumingfoundation. com/giap/2016/03/street-artist-blu-is-erasing-all-the-murals-he-painted-in-bologna/

7 https://news.artnet.com/art-world/moschino-designer-jeremy-scott-sued-street-artist-322947

8 https://www.vogue.co.uk/article/graffiti-artists-respond-roberto-cavalli-lawsuit

9 https://nypost.com/2017/04/28/mcdonalds-sued-by-graffiti-artists-for-using-their-work-in-ad/

10 https://www.standard.co.uk/business/corporate-vandalism-anger-as-brands-steal-street-art-for-ads-a3529681. html

11 Esta sobrecriminalização é evidente, por exemplo, na Lei $61 / 2013$, que estabelece o regime aplicável à prática do graffiti, que penaliza o infrator com uma multa de 100 a 25 mil euros. Desde então, o número de contra-ordenações tem vindo sistematicamente a subir.

12 Entrevista ao O Corvo para o artigo "Junta de Santo António e CML declaram guerra aos graffiti na Calçada do Lavra", 22 de março de 2016, em https://ocorvo.pt/ junta-de-santo-antonio-e-cml-declaram-guerra-aos-graffiti-na-calcada-do-lavra/

13 Informação disponível no sítio da Câmara Municipal da Amadora, em http://www.cm-amadora.pt/2485-conversas-na-rua-a-amadora-na-rota-da-arte-urbana. html

14 Informação disponível no sítio da Câmara Municipal de Loures, em https://www.cm-loures.pt/AtlasConteudo. aspx?DisplayId $=1196$

\section{Referências bibliográficas}

Aubry, A., Blein, A., \& Vivant, E. (2015). The promotion of creative industries as a tool for urban planning: the case of the Territoire de la culture et de la création in Paris Region. International Journal of Cultural Policy, 21(2), 121-138.

Bailey, C., Miles, S., \& Stark, P. (2004). Culture-Led Urban regeneration and the revitalization of identities in Newcastle, Gateshead and the North East of England. International Journal of Cultural Policy, 10(1), 47-65.

Bengtsen, P. (2015). Carelessness or curatorial chutzpah? On controversies surrounding street art in the museum. Konsthistorisk tidskrift/Journal of Art History, 84(4).

Câmara Municipal de Lisboa (2009). Carta Estratégica de Lisboa 2010-2024 - Um Compromisso para o Futuro da Cidade. Disponível online em http:// www.cm-lisboa.pt/municipio/camara-municipal/ carta-estrategica

Cameron, S., \& Coaffee, J. (2005). Art, gentrification and regeneration - From artist as pioneer to public arts. European Journal of Housing Policy, 5(1), 39-58. 
Campos, R. (2012). Graffiti writer as superhero. European Journal of Cultural Studies, 16(2), 155-170.

Campos, R. (2015). Youth, graffiti, and the Aestheticization of Transgression. Social Analysis, 59(3), 17-40.

Cardoso, J. A. (2007, fevereiro 28). A arte clandestina pinta ou suja as ruas?. Jornal Público. Retirado de https://www.publico.pt/2007/02/28/jornal/aarte-clandestina-pinta-ou--suja-as-ruas-178226

Costa, P., \& Lopes, R. (2015). Urban Design, Public Space and the Dynamics of Creative Milieux: A Photographic Approach to Bairro Alto (Lisbon), Gràcia (Barcelona) and Vila Madalena (São Paulo). Journal of Urban Design, 20(1), 28-51.

Costa, P. (2018). Práticas artísticas e espaço urbano: renovando compromissos com a observação etnográfica. Etnográfica, 22(2), 389-394.

Dickens, L. (2008). Placing post-graffiti: the journey of the Peckham Rock. Cultural Geographies, 15, 471-494.

Franklin, A. (2018). Art tourism: a new field for tourist studies. Tourist Studies, 18(4), 399-416.

Gainza, X. (2017) Culture-led neighbourhood transformations beyond the revitalisation/gentrification dichotomy. Urban Studies, 54(4), 953-970.

Guinard, P., \& Molina, G. (2018). Urban geography of arts: The co-production of arts and cities. Cities, 77, 1-3.

Hall, T., \& Robertson, I. (2001). Public Art and Urban Regeneration: Advocacy, claims and critical debates. Landscape Research, 26(1), 5-26.

Häussermann, H., \& Siebel, W. (1993). Die Politik der Festivalisierung und die Festivalisierung der Politik. Große Ereignisse in der Stadtpolitik. In H. Häussermann \& W. Siebel (Eds.) Festivalisierung der Stadtpolitik: Stadtentwicklung durch große Projekte. Leviathan. Sonderheft13. Opladen: Westdeutscher Verlag, 7-31.

Henningsen, E., Håkonsen, L., \& Løyland, K. (2015). From institutions to events - structural change in Norwegian local cultural policy. International Journal of Cultural Policy, 23, 352-371.

Iveson, K. (2010). The wars on graffiti and the new military urbanism. City: analysis of urban trends, culture, theory, policy, action, 14(1-2), 115-134.

Jacob, D. (2013). The Eventification of Place: Urban Development and Experience Consumption in Berlin and New York City. European Urban and Regional Studies, 20(4), 449-459.

Lacy, S. (Ed.) (1994). Mapping the terrain: new genre public art. Bay Press.
Ley, D. (2003). Artists, aestheticisation and the field of gentrification. Urban Studies, 40(12), 2527-2544.

Liu, Y. (2012). Cultural Events and Cultural Tourism Development: Lessons from the European Capitals of Culture. European Planning Studies, 22(3), 498-514.

Lombard, K. (2013). From Subways to Product Labels: The Commercial Incorporation of Hip Hop Graffiti. Visual Communication Quarterly, 20(2), 91-103.

Markusen, A. 2004. Targeting Occupations in Regional and Community Economic Development. Journal of the American Planning Association, $70(3), 253-268$

Markusen, A., \& G. Schrock (2006). The Distinctive City: Divergent Patterns in Growth, Hierarchy and Specialization. Urban Studies 43(8), 1301-1323.

Pavoni, A. (2015). Resistant legacies. Annals of Leisure Research, 18(4), 470-490.

Pussetti, C., \& Barros, V. (2012). The care of the immigrant self: technologies of citizenship and the healthcare sector. International Journal of Migration, Health and Social Care, 8(1), 42-50, doi.org/10.1108/17479891211231400

Pussetti, C., \& Barros, V. (no prelo). Geographies of Public Art and Urban Regeneration in Lisbon. In F. Martinez (Ed.), Politics of Recuperation. Repair and Recovery in Post-crisis Portugal. Londres: Bloomsbury.

Radice, M., \& Boudreault-Fournier, A. (Eds.) (2017). Urban Encounters. Art and the Public. McGill-Queen's University Press.

Rankin, K.N. (2011). Assemblage and the politics of thick description. City, 15(5), 563-569.

Ren, Hai. (2007). The landscape of power. Imagineering consumer behavior at China's Theme Park. In Scott Lukas (Ed.), The Themed Space: Locating Culture, Nation and the Self, Lextington Books, 97-112.

Skrede, J. (2015). What may culture contribute to urban sustainability? Critical reflections on the uses of culture in urban development in Oslo and beyond. Journal of Urbanism: International Research on Placemaking and Urban Sustainability, 9(4), 408-425.

Teixeira Pinto, A. (2018). The Art of Gentrification: The Lisbon Version. Afterall: A Journal of Art, Context and Enquiry, 45, 88-97.

Young, A. (2014). Cities in the city: Street Art, Enchantment, and the Urban Commons. Law \& Literature, $26(2), 145-161$.

Zukin, S. (1995). The Cultures of Cities. Malden and Oxford: Blackwell Publishing.

Esta obra está licenciada com uma Licença Creative Commons Atribuição - 4.0 (CC BY 4.0).

Recebido a 24/05/2019. Aceite para publicação a 18/07/2019

Chiara Pussetti (chiara.pussetti@ics.ulisboa.pt). Instituto de Ciências Sociais, Universidade de Lisboa, Av. Prof. Aníbal Bettencourt 9, 1600-189 Lisboa.

Vitor Barros (vitordavid.barros@gmail.com). Instituto de Ciências Sociais, Universidade de Lisboa, Av. Prof. Aníbal Bettencourt 9, 1600-189 Lisboa. 